\title{
Laboreal
}

Volume $5 \mathrm{~N}^{\circ} 2$ | 2009

Varia

\section{Os riscos profissionais e a sua gestão em contexto : dois objectos para um objectivo de formação}

\section{comum}

Los riesgos profesionales y su gestión : dos objetos con el mismo propósito de formación

Les risques professionnels et leur gestion en situation : deux objets pour un seul objectif de formation

Occupational risks and their management: two objects with the same training purpose

\section{Christine Vidal-Gomel, Paul Olry e Youcef Rachedi}

\section{OpenEdition}

\section{Journals}

\section{Edição electrónica}

URL: http://journals.openedition.org/laboreal/9689

DOI: 10.4000/laboreal.9689

ISSN: 1646-5237

\section{Editora}

Universidade do Porto

\section{Refêrencia eletrónica}

Christine Vidal-Gomel, Paul Olry e Youcef Rachedi, « Os riscos profissionais e a sua gestão em contexto : dois objectos para um objectivo de formação comum », Laboreal [Online], Volume 5 NN$^{0} 2$ 2009, posto online no dia 01 dezembro 2009, consultado o 10 outubro 2019. URL : http:// journals.openedition.org/laboreal/9689; DOI : 10.4000/laboreal.9689

Este documento foi criado de forma automática no dia 10 outubro 2019.

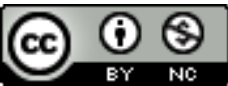

Laboreal está licenciado com uma Licença Creative Commons - Atribuição-NãoComercial 4.0 Internacional. 


\section{Os riscos profissionais e a sua gestão em contexto : dois objectos para um objectivo de formação comum}

Los riesgos profesionales y su gestión : dos objetos con el mismo propósito de formación

Les risques professionnels et leur gestion en situation : deux objets pour un seul objectif de formation

Occupational risks and their management: two objects with the same training purpose

Christine Vidal-Gomel, Paul Olry e Youcef Rachedi

\section{NOTA DO EDITOR}

Manuscrito recebido em : Maio/2009

Aceite após peritagem : Outubro/2009

Agradecimentos:

Esta pesquisa beneficiou de um financiamento da Direç̧ão Regional do Trabalho (CT 3).

Queremos também agradecer a todos os actores que, no decorrer dos diferentes estudos, permitiram a sua realização.

A. Camus e F. Rehane, durante a realização das suas teses de master 1 em psicologia ergonómica da Universidade Paris 8 - Vincennes - Saint-Denis (respectivamente em 2005 e 2007), contribuíram para a recolha dos dados.

1 O objectivo deste artigo é de considerar a formação para a prevenção dos riscos profissionais propondo uma reflexão sobre as actividades de gestão destes riscos pelos operadores, ou seja, identificação e tratamento das situações que comportam riscos de acidentes de trabalho. Assim, o quadro de análise utilizado articula os contributos da ergonomia, se interessa pelo funcionamento do sistema de trabalho e pelos 
determinantes da actividade dos operadores para transformar as situações, e os contributos da didáctica profissional, que explora o papel essencial da conceptualização no desenvolvimento das competências profissionais com vista à formação (Samurçay \& Pastré, 2004 ; Pastré, Mayen \& Vergnaud, 2006).

2 Antes de avançar mais no nosso estudo, é necessário situar brevemente essas duas abordagens e esclarecer quais os desafios que resultam desta utilização cruzada. De facto, as ligações entre a ergonomia de tradição francófona e a formação já são antigas

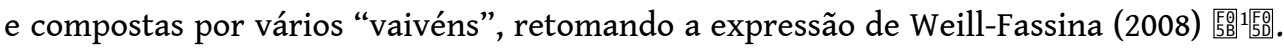
Esquematicamente, a ergonomia está mais vocacionada para a transformação das

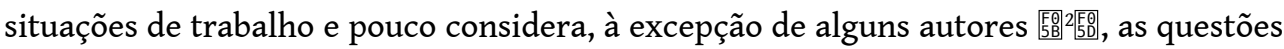
da formação. A partir dos anos 90, o interesse pela formação aumenta, nomeadamente com a implementação de intervenções participativas e fixa como objectivo formar actores em análise ergonómica do trabalho para transformar as situações, o que contribui também para o desenvolvimento das competências profissionais. A análise ergonómica do trabalho torna-se então objecto da formação e, no final dessa formação, uma ferramenta para os participantes (Lacomblez, 2001). Esta abordagem integra um objectivo duplo : contribuir para o desenvolvimento das competências profissionais e para a prevenção dos riscos associando formação e transformação das situações de trabalho (Lacomblez, 2001; Teiger \& Lacomblez, 2005, 2006). No entanto nessa fase, o número reduzido de operadores envolvidos - os participantes do estudo e/ou formação -, deixa em suspenso a extensão da formação a um ramo profissional ou uma profissão.

3 A didáctica profissional desenvolveu-se apoiando-se quer nos contributos da ergonomia - trata-se nomeadamente dos trabalhos de Leplat (Leplat \& Cuny, 1977 ; Leplat, 1997) e de Montmollin (1974) que consideram a análise do trabalho como preliminar da formação - quer nos contributos da psicologia do desenvolvimento, tais como os trabalhos levados a cabo por Vergnaud (1990) que destacaram a importância dos processos de conceptualização e o papel das mudanças conceptuais no desenvolvimento (Vidal-Gomel \& Rogalski, 2007). Ao constituir-se, a didáctica profissional também herdou dos projectos de ciências da educação, as quais em França reúnem aquilo a que se poderia chamar as "ciências da formação", e propõe de preferência um modelo de instrução directa (Lacomblez, 2001) - um formador transmite um ensinamento. Para conceber o conteúdo deste ensino, a didáctica profissional procura identificar os "saberes profissionais de referência" a partir da análise do trabalho. Constituem "categorias de objectos e de tratamentos comuns às práticas eficazes" face às categorias de situações (Rogalski \& Samurçay, 1994, p. 43). Esta abordagem permite assim elaborar os conteúdos de formação com base na actividade de trabalho e abranger um público mais alargado. Permanece a questão da transformação das situações de trabalho pois, como relembra Clot retomando os propósitos de Wisner, os pedidos de formação vindos das empresas escondem frequentemente problemas de condições de trabalho (Clot, et al,. 2005). Para além disso, o pedido é geralmente efectuado para os operadores de "primeira linha", quando, muitas vezes, como iremos constatar, é o conjunto do sistema de trabalho e seu funcionamento que deveria estar central no pedido.

o desafio passa a ser, para nós, empreender uma análise do trabalho destinada a contribuir para a concepção de formações em gestão dos riscos profissionais, que tomem em consideração as condições de trabalho com vista a viabilizar esta gestão e contribuir para a prevenção dos riscos profissionais. 
5 Esta dupla abordagem foi implementada no decorrer da realização de uma pesquisa sobre os riscos profissionais ligados à entrega de betão num estaleiro (Vidal-Gomel, Olry, Jeanmougin, \&, Lanoë, 2005 a e b). Incide, mais precisamente, sobre os riscos eléctricos gerados entre máquinas e linhas eléctricas aéreas existentes no local [3]. É constituída por vários estudos que foram efectuados em diversas empresas pertencentes a grandes grupos, principalmente do sector "pedreiras e materiais". Em França, a entrega de betão está ligada a três ramos profissionais - as pedreiras e materiais, o transporte ou os serviços -, o que torna mais complexo o recenseamento dos acidentes de origem eléctrica durante este tipo de actividade com base nos dados da Caixa Nacional de Segurança Social dos Trabalhadores Assalariados (CNAMTS) [ ${ }^{4}$. De acordo com um dos sindicatos profissionais ligado ao ramo "pedreiras e materiais", os acidentes de origem eléctrica são raros (cerca de 6 por ano) mas graves tendo em conta as características do perigo (electricidade de alta ou média tensão), e várias pessoas podem ser vítimas do mesmo acidente. A título de exemplo, os contactos com uma linha eléctrica aérea representam uma parte importante do conjunto das causas de acidentes de origem eléctrica nos Estados Unidos (Cawley \& Homce, 2003 ; Janicak, 2008), e são a segunda causa de morte, a seguir às quedas, no sector da construção civil em Taiwan (Chi, Yang, \& Chen, 2009). Baseado na análise dos riscos de contacto entre uma máquina de entrega de betão e uma linha eléctrica aérea, o nosso estudo sobre o trabalho dos condutores de máquinas de entrega de betão - que também designaremos por "operadores de entrega de betão" - pretende ainda determinar as interaç̧ões com outros riscos, com que os operadores se deparam.

6 Numa primeira fase, apresentaremos um quadro teórico articulando ergonomia e didáctica profissional para abordar a gestão dos riscos. A seguir apresentaremos o funcionamento do sistema de trabalho da entrega de betão. Focaremos então os saberes profissionais de referência passíveis de serem a essência de uma formação, baseandonos simultaneamente na análise da tarefa e da regulamentação, e sobre entrevistas e observações efectuadas em situação. Em conclusão, voltaremos à nossa utilização cruzada de pontos de vista oriundos da ergonomia ou da didáctica profissional para elaborar as pistas de reflexão que permitirão formar os operadores e transformar as situações de trabalho.

\section{Gestão dos riscos profissionais e formação : um quadro de análise articulando ergonomia e didáctica profissional}

7 Do ponto de vista da ergonomia, ao contrário de outras abordagens da prevenção dos riscos profissionais, os danos (acidentes de trabalho, doenças profissionais e/ou desgastes materiais) não são considerados apenas como o resultado de um encontro entre um operador e um perigo, são interpretados mais como um fracasso dos compromissos operatórios realizados por um ou vários operador(es) em situação (Bourgeois \& Van Belleghem, 2003) para enfrentarem os objectivos contraditórios do sistema de trabalho. A noção de regulação revela o processo desenvolvido pelos operadores para construir este tipo de compromisso. Pode ser definida como o conjunto das "modificações do comportamento individual e colectivo dos operadores para dar resposta às exigências das situações" (González \& Weill-Fassina, 2005). Depois de Leplat (2008 b) que se apoia nos contributos das teorias da actividade, considera-se 
que a mesma acção pode conter múltiplos motivos e metas, o que leva a diferenciar "regulações centradas nas tarefas" e "regulações centradas nos sujeitos" (p.28). 0 autor fornece alguns exemplos disso: os compromissos que devem ser assumidos entre produtividade e segurança dependem de regulações centradas nas tarefas, enquanto que os compromissos a assumir entre manter a sua saúde, preservar o seu emprego, etc. dependem de regulações centradas nos motivos. Ao se interessarem por actividades de serviço, Caroly e Weill-Fassina (2007) ou González e Weill-Fassina (2005) mostraram bem a necessidade de ter em conta estes dois tipos de regulações. Inscrevem-se num modelo que considera quatro pólos antagonistas:

- um pólo "Sistema" relativo à empresa com as suas metas e meios disponíveis (material, equipamento, regras, procedimentos, estrutura hierárquica);

- um pólo "Uso de Si" relativo ao agente com as suas próprias metas, a sua subjectividade, formação, experiência, as suas possibilidades fisiológicas e psicológicas, o sentido que ele atribui ao seu trabalho ;

- um pólo "outros" relativo às metas, obrigações e exigências dos outros (colegas da mesma profissão, equipas inter-profissionais, rede de parceiros) ;

- um pólo "pessoa-a-quem-se-destina-o-serviço"; chamada consoante os casos "cliente", "paciente", "beneficiário", "utente”, "público", [...] etc. (Caroly \& Weill-Fassina, 2007, p. 87).

8 Nalguns casos, os compromissos elaborados permitem manter um equilíbrio entre eficácia e saúde no trabalho (Gaudart \& Weill-Fassina, 1999), mas podem revelar-se prejudiciais à saúde e/ou à segurança dos operadores. A noção de "situação limite" permite dar conta de situações nas quais o operador é levado a fazer escolhas que não permitem reagir da melhor maneira aos riscos e que podem levar a uma situação indutora de acidentes (Benchekroun, Bourgeois, \& Hubault, 2002; Bourgeois \& Van Belleghem, 2003).

9 Os compromissos estabelecidos pelos operadores dependem das margens de manobra, ou seja, do espaço de liberdade de que dispõem para responder às variabilidades intra e inter-individuais, e à diversidade e variabilidade das características das situações de trabalho (das matérias primas, dos produtos, dos materiais mas também das competências dos colegas ou outros actores das situações de trabalho, ou ainda acasos, incidentes, etc.) (Coutarel, Daniellou \& Dugué, 2003). As margens de manobra dependem da organização do trabalho mas também das competências dos operadores. Assim, Puéyo (1999) mostrou que os auto-controladores mais velhos, que trabalham na laminagem a frio na siderurgia, dispõem de competências que lhes permitem por em prática diversos tipos de estratégias, e por consequência aumentar a sua margem de manobra, e, deste modo, a própria eficiência de trabalho. Por outro lado, as actividades de regulação exigem compreender, estabelecer decisões para a acção e agir em consonância nas situações. As actividades de diagnóstico / prognóstico e antecipação passam assim a ser realçadas, sendo caracterizadas por Amalberti e Hoc (1999) como actividades de diagnóstico cujo objectivo é elaborar decisões de acção.

10 A abordagem da didáctica profissional considera a conceptualização na e para a acção como um ponto chave das competências profissionais e do seu desenvolvimento (Samurçay \& Pastré, 2004 ; Pastré, Mayen \& Vergnaud, 2006). Dois destes quadros de análise permitem mostrar, de maneira complementar, os recursos necessários para compreender e actuar nas situações, e podem orientar a identificação de saberes profissionais de referência : "a estrutura conceptual das situações" (Pastré, 2005) e "os conhecimentos operacionais” (Rogalski \& Marquié, 2004). 
11 A estrutura conceptual das situações está organizada à volta da acção a tomar e assenta na elaboração do diagnóstico da situação. Integra três componentes :

- Conceitos organizadores da actividade : "as dimensões, extraídas do real na sua globalidade, que vão permitir fundamentar o diagnóstico da situação" (Pastré, 2005, p. 243). Trata-se de conceitos-em-acto (Vergnaud, 1990) ou de conceitos pragmáticos (Samurçay \& Pastré, 1995), que apresentam várias diferenças (Vidal-Gomel \& Rogalski, 2007) : os conceitos pragmáticos podem ser verbalizados e são transmitidos no seio das comunidades profissionais, ao contrário dos conceitos-em-acto. A acção eficaz dá legitimidade e pertinência aos conceitos pragmáticos enquanto que os conceitos-em-acto podem ser verdadeiros ou falsos.

- Indicadores: "observáveis, naturais ou instrumentados, que permitem, para determinada situação, identificar o valor assumido pelos conceitos organizadores. 0 equivalente de uma relação significante-significado liga os indicadores aos conceitos" (Pastré, op. cit.).

- Classes de situações : permitindo "orientar a acção em função do diagnóstico efectuado, e que advêm dos valores assumidos pelos conceitos organizadores” (Pastré, op. cit.).

12 À medida que se desenvolvem as competências profissionais, os conceitos organizadores da actividade enquadram-se no coração de uma rede de relações entre variáveis da situação e conceitos pertinentes para a compreender ou nela actuar. A extensão dessa rede orienta o operador no sentido de melhor diferenciar as classes de situações, o que lhe permite efectuar diagnósticos de situação mais precisos (Samurçay \& Pastré, 1995).

13 Este primeiro quadro de análise leva-nos a compreender mais particularmente os diagnósticos sustentados no objecto da acção e as suas características: prensa a injecção a regular (em plasturgia), central nuclear que o operador deve dirigir, incêndio florestal que deve ser controlado, etc. Este tipo de abordagem analisa de forma fina os diagnósticos produzidos mas tem dificuldade em ordenar a variedade dos conhecimentos necessários à regulação do sistema de trabalho.

14 A noção de "conhecimentos operacionais" (Rogalski \& Marquié, 2004) permite apreender esta diversidade. De facto, inclui as componentes da estrutura conceptual das situações tendo ao mesmo tempo em conta :

- Os conhecimentos sobre o processo de trabalho (Boreham, Samurçay \& Fischer 2002) : tratase tanto de conhecimentos sobre o processo de fabrico, como de conhecimentos sobre o modo como os resultados do trabalho de um actor podem influenciar o trabalho dos outros no meio de um processo, de conhecimento sobre as regras do ofício (Cru, 1995), do que é permitido ou não no seio de um colectivo de trabalho ;

- O conhecimento dos casos particulares (conhecimentos proveniente da experiência, "episódicos"): trata-se de conhecimentos sobre disfuncionamentos precisos, sobre casos particulares ou raros, que resultam da experiência de um operador ou de um colega ;

- Os meta-conhecimentos como, por exemplo, conhecimentos sobre a sua própria experiência ou ainda conhecimentos sobre as situações que sabem que não dominam (Valot, Grau, \& Amalberti, 1993) ;

- Os conhecimentos exigidos para a actividade colectiva, como o conhecimento que cada um tem sobre as competências do outro (Valot, 2001), os referenciais operativos comuns (de Terssac \& Chabaud, 1990) ou modelos mentais partilhados (Cannon-Bowers, Salas, \& Converse, 1993).

15 Estes diferentes quadros de análise permitem caracterizar as dimensões das competências em jogo. Não são, no entanto, neste artigo, tanto as diferenças inter e intra- individuais que poderiam ser reveladas pela análise das competências que nos 
interessam. A análise das condições de segurança de trabalho dos operadores de entrega de betão, a avaliação dos riscos e a caracterização das competências são aqui orientadas na perspectiva de melhorar a formação. Trata-se de destacar os "saberes de referência" (Rogalski e Samurçay, 1994). Isto leva-nos a identificar, pelo menos parcialmente, características comuns às situações do domínio profissional considerado e características invariantes da actividade que permite o seu tratamento eficaz. Neste quadro, fixa-se como objectivo da formação a aquisição destes saberes profissionais previamente identificados.

Conceber situações de formação implica definir as situações que se pretendem dominar e transpô-las para a formação com vista a conseguir a aquisição destes saberes profissionais. Trata-se então, de acordo com a tipologia de Samurçay e Rogalski (1998), de "decompor" a situação (em tarefas e sub-tarefas, por exemplo); de "separar" (formando em primeiro lugar para o trabalho individual e a seguir para o trabalho colectivo, por exemplo); ou de "focalizar" (centrando a formação sobre um par de variáveis). São essas várias formas de efectuar escolhas sobre os elementos do par "actividade do sujeito-situação" que vão determinar as actividades e as conceptualizações para as quais as aquisições serão orientadas pela formação e as que serão adquiridas "no terreno" e de forma experiencial.

Antes de expor as nossas análises relativas aos saberes de referência, apresentaremos o funcionamento do sistema de trabalho de entrega de betão e as formações a que os operadores podem ter acesso.

\section{0 funcionamento do sistema de trabalho da entrega de betão}

O sistema de trabalho de entrega de betão é constituído pelo estaleiro onde será efectuada a entrega (estaleiros de particulares ou, mais frequentemente, uma empresa de construção civil de tamanho variável, ou ainda de obras públicas), a central de betão (empresa que receba a encomenda, fabrica o betão e aluga os serviços de uma empresa de entregas) e a empresa de entrega que emprega o entregador que irá efectuar a entrega (esquema 1). 
Esquema $1: 0$ sistema de trabalho da entrega de betão

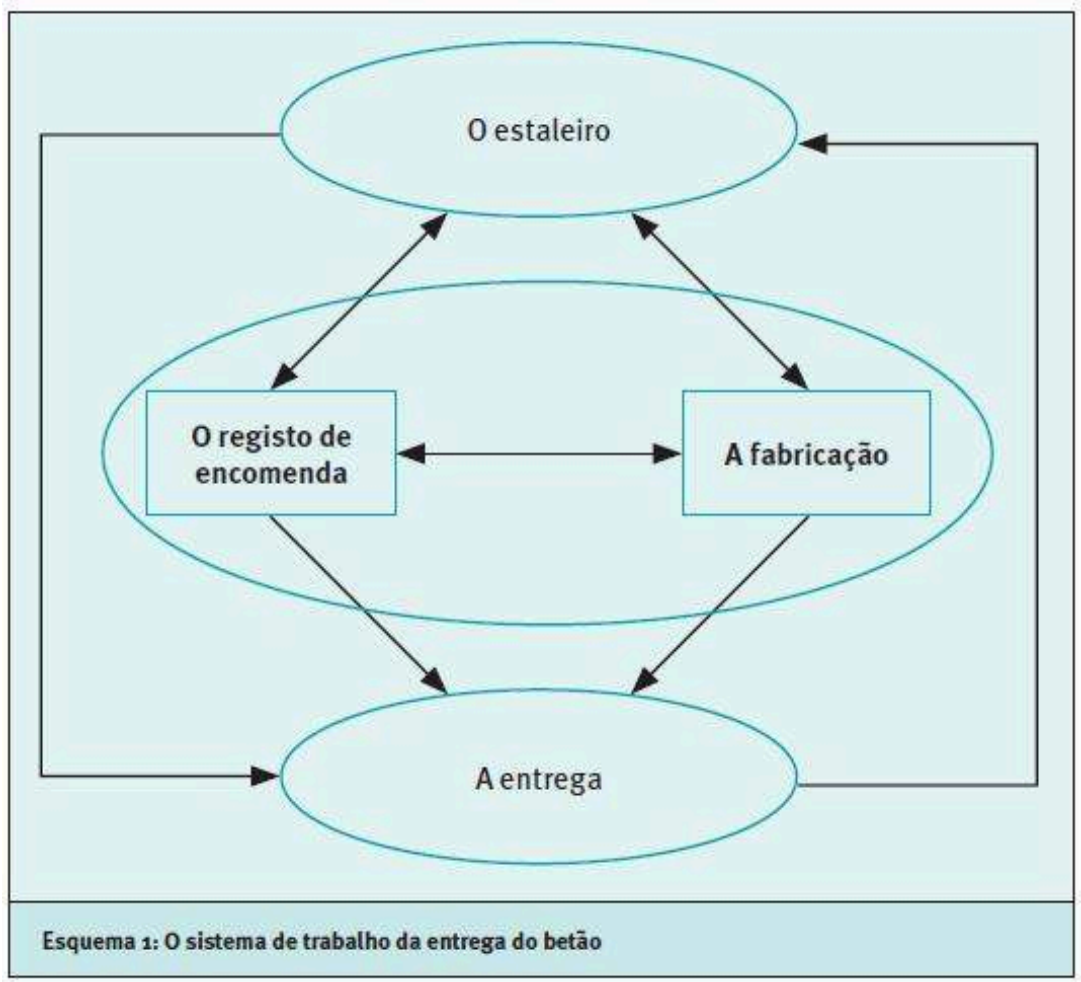

Na central de betão, o operador de entrega de betão pega na nota da encomenda, informa-se eventualmente do itinerário, carrega a cuba (quadro 1). A partir daí fica responsável pela execução da encomenda, do transporte até à entrega da guia de remessa assinada pelo encarregado do estaleiro-cliente.

O nosso estudo incide sobre três tipos de máquinas de entrega :

- "Auto-Betoneiras" : equipadas com uma "misturadora", cuba de armazenamento e de mistura do betão, e eventualmente com um tapete transportador de betão (um braço articulado de 10 a 18 metros desdobra-se e permite encaminhar o betão para o local de entrega através de um tapete rolante). Daqui em diante, chamar-lhes-emos "tapetes".

- "Auto-betoneiras com bomba" : equipadas com uma "misturadora", cuba e braço articulado (16 a 28 metros). A técnica de bombagem do betão consiste em empurrar o betão para dentro de uma conduta, por intermédio de uma bomba (pressão de cerca de 50 bars). No meio profissional são designadas por "bombas-misturadoras", designação que iremos manter.

23 - "Auto-bombas de betão" : não estão equipadas com tambor, dispõem de braços articulados de 18 a 58 metros (para uma bomba de $58 \mathrm{~m}$, alcance vertical máximo de 57 $\mathrm{m}$ e alcance horizontal de $50 \mathrm{~m}$, o braço articulado é composto de 5 articulações). Passaremos a denominá-las "auto-bombas".

Os dois primeiros tipos de máquinas são ditos "móveis" : estão equipados com cubas, podendo ser efectuadas várias entregas no prazo de meio-dia. A cuba é carregada na "central de betão" (empresa que fabrica o betão), o betão é encaminhado e entregue no estaleiro. 0 operador de entrega de betão volta depois à central para efectuar uma nova entrega. As auto-bombas são consideradas máquinas "fixas": são instaladas num 
estaleiro durante pelo menos meio-dia. São alimentadas com betão por máquinas equipadas de cubas que fazem o percurso entre a central e o estaleiro.

Quadro 1 : Características dos diferentes tipos de máquinas

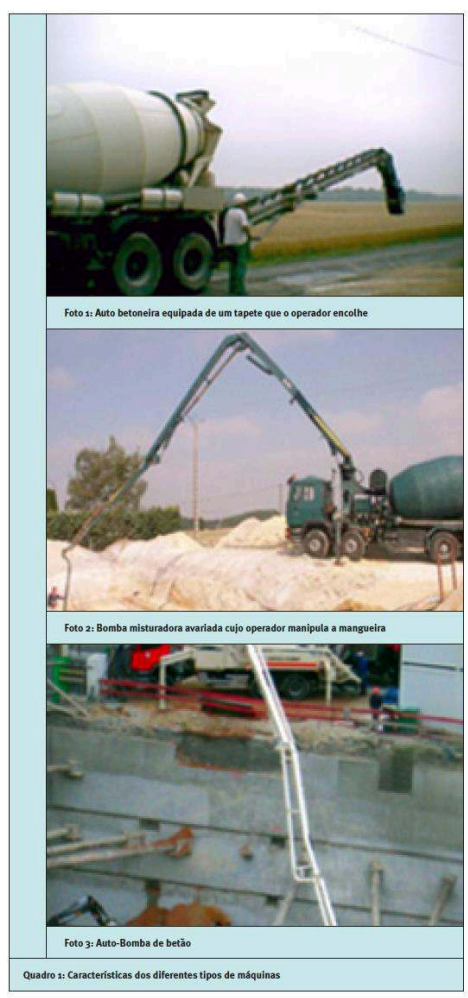

A entrega é consecutiva a uma encomenda efectuada pelo encarregado do estaleiro que contacta directamente a central de betão. $O$ prazo entre a recepção da encomenda e a entrega é geralmente de "ontem para amanhã" (excerto de entrevista de um operador, quadro 2, a seguir) tornando-se difícil efectuar qualquer visita prévia para detectar eventuais perigos, tais como presença de linha eléctrica aérea [5], e muito menos estabelecer um plano de prevenção. $O$ operador de entrega de betão deve identificá-los e lidar sozinho com a situação na altura da entrega.

No estaleiro, o entregador entra em contacto com o encarregado do estaleiro, ou, na falta deste, com um companheiro [NT16]. Com base nas indicações que lhe são fornecidas, ele instala a máquina para descarregar. Uma vez efectuada a descarga, a máquina tem que ser lavada, o que obriga a deslocá-la.

Os acidentes de origem eléctrica acontecem mais nas fases de esticar ou arrumar os braços articulados ou os tapetes ou ainda na altura de lavagem do tapete : este deve ser estendido para ser lavado com água, podendo dar origem a acidente caso se prenda com uma linha eléctrica aérea (Dei-Salvi, Paques, \& Gillet, 1992; Vidal-Gomel, Olry, Jeanmougin \& Lanoë, $2005 \mathrm{a} \mathrm{e} \mathrm{b).}$

28 A colocação da máquina é mais complexa quando se trata de uma auto-bomba ou de uma bomba-misturadora (quadro 1). De acordo com o tamanho da lança a estender e do seu peso, será necessário estabilizar a máquina, o que nem sempre é fácil (falta de espaço para instalar os estabilizadores, terreno enlameado, inclinado, etc.). Para além disso a limpeza das condutas da bomba é efectuada com a ajuda de uma bola de 
borracha para permitir retirar o betão das suas paredes. Esta operação obriga a accionar a bomba e a ejecção da bola é uma fase que se torna por vezes perigosa.

\subsection{Uma actividade sob constrangimento de tempo}

29 A actividade de entrega é determinada em grande parte pela central de betão e pelas características do estaleiro (Vidal-Gomel, et al., 2005 a ; 2007).

$\mathrm{Na}$ central de betão, a pessoa encarregada do atendimento telefónico anota as encomendas e faz o planeamento : define o número de entregas que serão efectuadas e o tempo de trabalho do operador de entrega de betão, que pode ser variável. É o resultado de um ajustamento tão próximo quanto possível dos pedidos dos clientes. Varia de um dia para o outro em função das encomendas : "tanto podemos acabar às 17 h30 como às 19h30" explica um operador. No verão, período em que há muitas encomendas, observámos que jornadas de 10 horas não são excepção. A fabricação do betão determina também a actividade do operador de entrega de betão, até porque a qualidade do betão condiciona as relações com o estaleiro cliente. De facto, assim que se inicia a entrega, o operador de entrega de betão tem o tempo contado. 0 betão carregado na cuba respeita as normas de qualidade, mas continua a transformar-se ao longo do percurso, em função das condições climáticas (calor, humidade), da duração do transporte, do processo de amassar que ocorre na cuba, etc. Por isso, quando chega ao estaleiro, o betão pode, por exemplo, corresponder às normas mas ser considerado demasiado "duro", o que pode levar a discussões sobre a necessidade de o humidificar.

\subsection{Uma actividade com riscos}

O estado do estaleiro e a sua conduta são determinantes nos riscos a gerir : presença de uma linha eléctrica aérea, mas também condições de acesso, obstrução, condições de visibilidade (presença de obstáculos que escondem a linha), etc. Os recursos disponíveis, tanto materiais como humanos, também são determinantes. Deles dependem o tipo de descarga que virá a ser efectuada bem como o tempo necessário para tal.

32 As competências dos companheiros presentes no estaleiro são determinantes para a gestão dos riscos : a entrega é uma actividade colectiva, que leva o operador de entrega de betão a gerir riscos para ele e para as pessoas presentes no estaleiro. Por exemplo, quando uma entrega é efectuada com tapete, o operador de entrega de betão deve ajustar a sua posição regularmente : devido às vibrações, desloca-se lateralmente, o que se pode acentuar quando o estaleiro se encontra num terreno inclinado, mesmo que ligeiramente. No decorrer das nossas observações, reparámos que alguns companheiros pareciam não saber muito bem avaliar estas características, o que os levava por vezes a tomar decisões arriscadas e a fazer com que o operador de entrega de betão fosse forçado a intervir (Vidal-Gomel et al., 2007).

Por outro lado, a evolução de um arco eléctrico é pouco previsível : um "companheiro" que não esteja envolvido na entrega mas que esteja a utilizar uma ferramenta condutora de electricidade (carrinho de mão por exemplo) pode ser uma vítima. A sua chegada pode por isso preocupar tanto os companheiros como o operador de entrega de betão. Tanto mais que, quando a entrega é efectuada com uma bomba-misturadora ou uma auto-bomba, o entregador coloca-se geralmente perto do ponto de entrega e 
dirige a máquina com um comando à distância, e pelo menos um dos companheiros segura na ponta do braço articulado e movimenta-o de forma a facilitar a actividade de distribuição do betão dos outros companheiros. No caso de haver contacto com uma linha eléctrica aérea, o operador que segura na ponta será a principal vítima (Dei-Salvi et al., 1992 ; Vidal-Gomel et al., 2005 a e b).

Deste modo, se a função de operador de entrega de betão se encontra oficialmente descrita, as funções efectivas integram uma responsabilidade no que diz respeito à qualidade do betão entregue, à rapidez do serviço (margem temporal, ...), e à segurança da entrega.

\section{As formações propostas aos operadores}

Não existe actualmente nenhuma obrigação específica em termos de formação ou de certificação para exercer o ofício de operador de entrega de betão de betão, para além da carta de condução de pesados. No decorrer do nosso estudo, registámos três tipos de formações eventualmente propostas aos operadores: uma formação proposta aos operadores principiantes quando entram para a empresa, formações eventualmente facultadas no seio das grandes empresas e a formação "Pôr em funcionamento com segurança as bombas de betão", proposta por um ramo profissional.

36 A formação facultada aos operadores principiantes, na altura da sua entrada na empresa, é uma formação por "companheirismo". Em primeiro lugar, os operadores recebem formação para aprenderem a utilizar o comando à distância, por exemplo, num parque de estacionamento. A seguir, efectuam o trabalho no terreno na presença de um operador mais antigo. Este não está especialmente formado para exercer essa função de tutor. A duração da formação parece variar muito de empresa para empresa. Alguns operadores falaram-nos de alguns dias de formação, outros disseram que a formação terminava quando eles se considerassem aptos para o trabalho, outros ainda afirmaram que tinha tido uma duração de dois meses.

37 Algumas empresas organizam o percurso profissional dos operadores de entrega de betão de forma a que eles conduzam as máquinas mais complicadas só depois de terem adquirido uma certa experiência. Essas empresas teriam assim um sistema que combina formação no terreno, aumento da complexidade das tarefas em função da experiência e evolução das carreiras. Os operadores de entrega de betão utilizariam inicialmente máquinas equipadas com tapetes, depois as bombas misturadoras, e depois então as auto-bombas (das menos potentes às mais potentes). Corresponde de facto com o percurso dos 4 operadores condutores de bombas misturadoras e de auto-bombas que entrevistámos e de 2 dos 3 operadores que participaram na formação "Pôr em funcionamento com segurança as bombas de betão" (quadro 2). No entanto, tal não acontece sistematicamente. Alguns operadores principiantes na profissão também conduzem auto-bombas ou bombas misturadoras, nomeadamente porque surgem problemas de saúde com a idade e o exercício do posto - por exemplo devido a posturas constrangedoras e a transporte de cargas (Vidal-Gomel et al., 2005a) - e porque alguns operadores experientes recusam manobrar auto-bombas ou bombas misturadoras que acham demasiado prejudiciais à sua saúde (o transporte de cargas é mais importante com uma máquina equipada de tapete). formações são ministradas por operadores responsáveis pela segurança (geralmente 
engenheiros de segurança). Nesses casos trata-se de formações curtas (algumas horas), ministradas em sala, a propósito de um risco específico, de procedimentos ou de regras de segurança.

O ramo profissional "carreiras e materiais" propõe uma formação de dois dias, em sala, intitulada "Pôr em funcionamento com segurança as bombas de betão". Durante esses dois dias são abordados os diversos tipos de riscos, os procedimentos e as regras de segurança a aplicar, bem como a manutenção de primeiro nível.

Filmámos uma sessão de formação de dois dias. Apenas três operadores estavam presentes. Esta fraca participação, segundo os intervenientes do ramo com quem nos encontrámos, é frequente e coloca problemas de rentabilidade da formação. Na sessão observada :

- Foram apresentados os principais tipos de acidentes de trabalho (capotamento da máquina, acidente de origem eléctrica, acidentes de viação), bem como as causas de acidentes, sempre focalizadas sobre "erros" dos operadores de entrega de betão - sendo evocado maus hábitos, desconhecimento dos riscos ou improvisação.

- o direito de recusar o trabalho em situações perigosas [7] foi apresentado e explicado.

- O formador deixava bastante espaço para debate e troca de experiência entre operadores que o solicitavam com frequência a partir das características das situações a que são expostos, o que remetia geralmente para o relembrar da regra ou do procedimento a aplicar. terreno" e quando se propõe formações mais estruturadas trata-se geralmente de formações "técnico-regulamentares".

42 Assim sendo, as formações actualmente ministradas parecem, pelo menos em relação às actividades de gestão de riscos dos operadores de entrega de betão que identificámos na análise prévia de funcionamento do sistema, desligadas da actividade dos operadores, embora por vezes assentes em aspectos fundamentais. O conhecimento da regulamentação e das regras de segurança é de facto uma necessidade. No entanto, mesmo para formar em regulamentação, as formações propostas poderiam ser melhoradas considerando não só as dimensões técnicas e regulamentares como também as relações existentes entre as características das situações, a actividade e os conceitos em jogo. A identificação dos saberes profissionais de referência foi conduzida nesse sentido.

\section{A gestão dos riscos de contacto com uma linha eléctrica aérea : quais os saberes profissionais de referência?}

43 Numa primeira fase, para identificar os saberes de referência, efectuámos uma análise da tarefa, baseando-nos na regulamentação existente, com vista a evidenciarmos classes de situações relativas ao risco de contacto com uma linha eléctrica aérea, procedimentos associados (procedimentos para evitar ou recuperar) e os conceitos subjacentes. Consideramos este conjunto como elementos para uma "teoria" do risco de contacto com uma linha eléctrica aérea. $O$ nosso interesse irá também para o conhecimento dos próprios operadores. Numa segunda fase, continuaremos a nossa caracterização dos saberes de referência salientando as dificuldades de gestão do risco em situação. Estes contributos serão apresentados em função de três fases: 
identificação do perigo, identificação do risco em situação e gestão dos riscos de contacto com uma linha eléctrica aérea em situação.

Quadro 2 : Metodologia geral do estudo

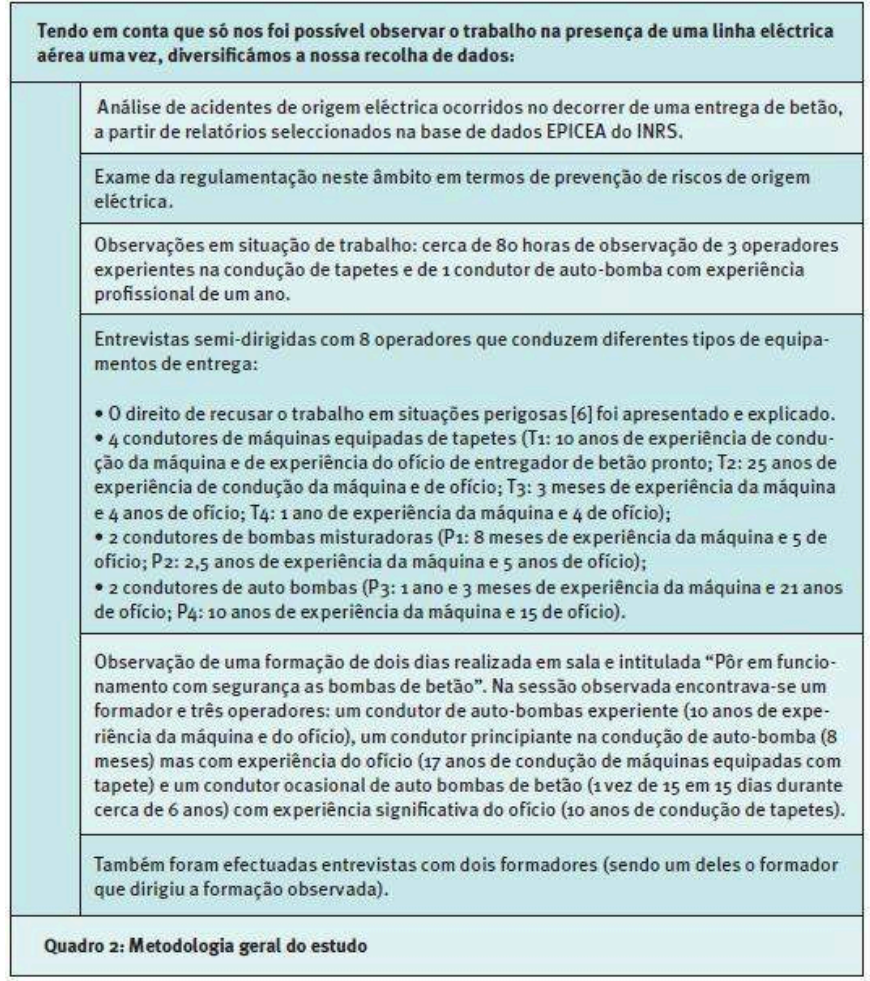

\subsection{Saberes profissionais de referência : elementos de uma teoria do risco de contacto com uma linha eléctrica aérea}

Mayen e Savoyant (1999), ao se interessarem pelos riscos ferroviários, propõem a noção de "teoria do risco" que reúne e integra "todos os elementos que permitem compreender" as situações de riscos. Neste quadro, as ferramentas e os procedimentos de segurança "não são dados originais mas sim respostas" que permitem enfrentar o risco (p.79). Baseado na análise da regulamentação (UTE C18-510, 1991), alguns elementos de uma "teoria" do risco de contacto com uma linha eléctrica aérea foram formalizados a partir dos elementos constituintes da estrutura conceptual das situações propostas por Pastré (2005), o que nos leva a diferenciar classes de situações, de procedimentos eficazes de gestão do risco associados a estas situações e dos conceitos em causa. Utilizado neste contexto, o termo de teoria $\left.{ }^{8}\right]$ fica reduzido a alguns elementos de uma tipologia do risco de contacto entre uma linha eléctrica aérea e uma máquina de entrega (ou de manutenção) equipada com um braço articulado. Ainda assim determina o âmbito da reflexão.

- A primeira classe de situação pode ser considerada com "situação nominal" : o operador identificou a presença de uma linha eléctrica aérea e aceitou fazer a entrega. Nesta situação, deverá efectuar a entrega mantendo-se a uma distância suficiente da linha eléctrica para evitar o contacto entre a linha e o braço articulado da máquina. Essa distância é chamada 
“distância mínima de aproximação" (DMA). Depende da tensão da linha eléctrica aérea (por exemplo, o DMA equivale a $2 \mathrm{~m}$ para $20 \mathrm{KV}$ ).

É calculada somando a distância mínima a respeitar para evitar a produção de um arco eléctrico, denominada "distância de tensão" [valor nominal da tensão multiplicado por $\mathrm{t}(\mathrm{t}=0,005)]$ e a distância de segurança, que permite ao operador "manter-se concentrado no seu trabalho sem se preocupar em demasia com a distância" em relação aos elementos sob tensão (é de $0,5 \mathrm{~m}$ em alta tensão).

As duas outras classes de situações correspondem a um incidente eléctrico que o operador pode eventualmente recuperar :

- Na primeira classe de situações, um contacto entre o braço articulado da máquina e a linha eléctrica acontece quando o operador se encontra no interior da cabine da máquina de entrega. $O$ procedimento de recuperação consiste em esperar o fim das descargas automáticas da linha eléctrica [] para sair da máquina, a fim de evitar tocar na massa metálica da máquina sob tensão estando em contacto com o solo e criando assim uma diferença de potencial, que resultaria na electrocussão do condutor.

Ao examinar 15 acidentes de origem eléctrica que ocorreram durante uma entrega (quadro 2), verificámos que 5 deles poderiam ter sido recuperados. Após o contacto entre a máquina de entrega e a linha eléctrica aérea, a recuperação falhou, nesses casos, porque o operador está simultaneamente em contacto com o solo e uma massa sob tensão (Vidal-Gomel, et al, 2005 a ; 2007). Este tipo de acidente não é excepção : DeiSvaldi, Paques e Gilet (1992), nas suas análises de acidentes relacionados com o contacto entre máquinas de estaleiros e linhas aéreas eléctricas sob tensão, identificaram acidentes semelhantes.

- No segundo caso, o operador encontra-se fora da cabine na altura do incidente. Devido ao contacto com a linha, a massa metálica da máquina sob tensão pode encontrar-se em contacto com o solo, o que origina uma zona de tensão : a partir da zona de impacto formase no solo um gradiente de potencial. Nesse caso, existe uma diferença de potencial importante a cada 0,8 $\mathrm{m}$ aproximadamente, que corresponde à distância de um passo de adulto. Ou seja, nesta área, o operador não pode dar uma passada normal mas sim deslocarse dando pequenos passos ou pequenos saltos para evitar ser electrizado. Deve ter em consideração a "tensão de passo".

A teoria de risco aqui especificada integra vários conceitos : a tensão de passo e a DMA, que são formas de ter em consideração ou evitar criar uma diferença de potencial. Esta está relacionada com as noções de arco eléctrico, ionização do ar, de massa, de resistência, etc., noções correntes de electricidade, mas nem sempre de acesso fácil para todos os operadores de entrega de betão.

Esta teoria não pode ser adquirida "no terreno" e a sua transmissão pelos seus pares pode tornar-se problemática. Por isso, quisemos saber como é que os operadores a formulavam; nas empresas que participaram no estudo os operadores receberam, de facto, formação sobre esses aspectos. Por isso, as entrevistas realizadas (quadro 2) foram analisadas sob este prisma.

Por um lado, à pergunta "quais os riscos a que estão sujeitos no vosso trabalho ?", a presença de linha eléctrica aérea num estaleiro é o primeiro risco espontaneamente citado pelos 8 operadores entrevistados. Para além disso, se o risco de arco eléctrico é conhecido e tomado em consideração por todos os operadores, 3 dos 8 entrevistados revelam não dominar nem a noção de arco eléctrico nem a de DMA : um deles fala de 
"arco de círculo", outro diz que não conhece a DMA, outro avalia-a a $2 \mathrm{~m}$ sem referir a importância da variação da tensão da linha - registamos que outras verbalizações parecem menos problemáticas: 2 operadores avaliam-na a 5-6 m, distância de segurança qualquer que seja o grau de variação da tensão da linha, e 3 não a referem, o que não significa que não a conheçam. Por fim, ninguém especifica os procedimentos de recuperação. Além disso, só 1 dos 3 operadores conhecia a DMA (o seu valor em função do grau de tensão), a tensão de passo e o procedimento associado.

51 Deste modo, a teoria do risco aparenta ser pouco conhecida por estes operadores, oriundos, no entanto, de empresas que facultam formação sobre o assunto. Assim, embora os operadores concebam os riscos ligados à presença de uma linha eléctrica aérea, e por isso compreendem a necessidade de respeitar uma DMA, desconhecem o seu valor preciso em função do valor da tensão da linha.

Estes resultados questionam as formações ministradas, que se desenrolam em sala, num formato de transmissão de conhecimentos académicos, supostos ser ulteriormente aplicados em situação. Estas formações parecem confundir informações dadas aos operadores com formação destinada a uma acção eficaz não podendo assim atingir um objectivo de prevenção.

\subsection{Saberes profissionais de referência e dificuldades de gestão do risco eléctrico em situação}

53 Com base nas entrevistas e observações, procurámos identificar os saberes de referência em causa na gestão dos riscos em situação, considerando que a teoria do risco de contacto com uma linha é necessária para essa gestão mas também insuficiente. É insuficiente, por um lado porque deve ser operacionalizada - ou mais exactamente "pragmatizada" no sentido que Pastré (2005) dá a este termo - para ser aplicada eficazmente em situação, e por outro lado, porque o risco eléctrico interage com outros riscos no decorrer da acção em situação e finalmente porque esta teoria apenas representa uma parte das competências necessárias para regular o sistema de trabalho.

Com vista a uma melhor apreensão dos saberes profissionais de referência, procurámos ter em consideração as dificuldades dos operadores de entrega de betão separando as diversas fases de trabalho : a identificação do perigo, a identificação do risco e a gestão do risco.

\subsubsection{A identificação do perigo}

55 A identificação do perigo remete-nos aqui para a identificação da presença de uma linha eléctrica. As condições meteorológicas ou a luminosidade podem representar obstáculos. Actualmente, a maioria das máquinas estão equipadas com detectores de linhas eléctricas aéreas que emitem um sinal e bloqueiam o braço articulado da máquina quando esta se aproxima de uma linha eléctrica aérea. o limite de desencadeamento do alarme encontra-se geralmente regulado ao nível da distância mínima de aproximação calculada com o nível de tensão mais elevado (DMA de 5 metros). Os detectores de linhas revelam-se ferramentas preciosas quando as condições de visibilidade são reduzidas (chuva, nevoeiro, luminosidade insuficiente, etc.). No entanto, a sua utilização levanta alguns problemas. Por um lado, alguns operadores 
assinalam problemas de fiabilidade. Por outro lado, em função da distância fixada, ao detectar uma linha eléctrica aérea a máquina bloqueia o braço. Porém, a linha identificada nem sempre incomoda, pode estar distante do ponto de entrega. No caso em que o operador pode decidir efectuar a entrega apesar da presença da linha, tem de passar em "marcha forçada". A expressão significa que o operador de entrega de betão ultrapassa as especificações de segurança e "desliga" o detector de linha. As empresas consideram então que ele tomou uma decisão de que é responsável com pleno conhecimento de causa. Do ponto de vista dos operadores, se o detector constitui um contributo real não impede no entanto que eles empreguem frequentemente a "marcha forçada". Se o detector é um alarme útil para a detecção da presença de linhas, em caso algum constitui uma ferramenta que possa ajudar a enfrentar o risco em situação e contribui, em caso de problema, para imputar todas as responsabilidades aos operadores de entrega de betão.

\subsubsection{A identificação de uma situação de risco e a gestão do risco de contacto}

Uma situação que apresenta um risco de contacto com uma linha eléctrica aérea é uma situação em que, tendo em conta a localização da máquina no estaleiro e a localização do ponto de descarga, o trabalho só poderá ser efectuado na proximidade da linha.

Durante uma entrevista, um operador descreveu-nos algumas características de uma situação em que ele recusou efectuar a descarga tendo em conta os riscos identificados.

"Ficávamos forçados a trabalhar na horizontal e perpendicularmente ao meu camião, ou seja, o alcance da lança estava no máximo, e como não podia tirar o meu patim no máximo, disse "não o faço, não quero fazê-lo"

Neste exemplo, o operador relata uma situação de trabalho na presença de uma linha eléctrica. Para efectuar a entrega, ele aplica uma regra "passar debaixo dos fios", sobre a qual voltaremos mais à frente. Um critério importante intervém no seu diagnóstico de situação : não é possível tirar completamente os estabilizadores da máquina (tendo em conta o estado do terreno, o estado de congestionamento do estaleiro ou talvez mais simplesmente o facto do local ser muito estreito). Por outro lado, ele tem de utilizar o alcance da sua lança no máximo colocando-a na horizontal e perpendicularmente ao camião. Arrisca virar a máquina. Implicitamente, ele mobiliza o conceito de "momento" que se pode definir como "a aptidão de uma força para fazer girar um sistema mecânico à volta de um certo ponto, chamado pivot. 0 "momento" funciona aqui como conceitoem-acto ; mobilizado para identificar o risco de capotamento da máquina, interage com o risco de contacto com a linha, gerindo-o aplicando uma regra : "é necessário passar debaixo da linha".

Observámos outra situação em que o risco de capotamento da máquina interage com o risco de contacto com a linha. O estaleiro estava situado numa zona urbana nos arredores de Paris. Uma linha eléctrica aérea passava por cima do passeio à frente da entrada para o estaleiro a fornecer, o estaleiro era um pequeno prédio em que era necessário encher a parte superior do segundo andar, placa do futuro terceiro. Para poder manter-se suficientemente afastado da linha esticando a lança da máquina (é necessário "desimpedir" a máquina da linha), o condutor teve de se afastar o máximo possível dentro do estaleiro. Tendo em conta a falta de espaço disponível, em comprimento e em largura, na altura de colocar os estabilizadores da auto-bomba, o condutor reparou que o estabilizador esquerdo da frente ia ficar à beira de um buraco 
do qual as terras poderiam desabar provocando assim o capotamento da máquina. 0 condutor colocou tábuas por cima do buraco para gerir esse risco. No entanto, durante toda a distribuição do betão, como a auto-bomba estava com pouca estabilidade e dava solavancos, apesar de estar no andar, aproximava-se das extremidades e inclinava-se frequentemente para olhar na direç̧ão do buraco e do estabilizador esquerdo da frente. Como não tinha sido colocada nenhuma protecção, corria o risco de cair. Aqui a noção de distância mínima de aproximação está integrada, bem como o conceito-emacto de momento. A gestão dos riscos de colidir com a linha e de capotamento da máquina levou a ter de enfrentar um terceiro risco : o risco de queda.

Nas entrevistas que efectuámos, a regra "passar debaixo da linha" é referida pelo conjunto dos operadores, qualquer que seja a máquina que utilizam, para falar de situações nas quais efectuam a entrega na presença de uma linha eléctrica aérea.

Para os condutores de máquinas equipadas com tapete, trata-se de passar debaixo da linha para esticar o tapete, o que constitui uma tarefa crítica. A distância mínima de aproximação parece ser levada em consideração ao ficar o mais longe possível da linha :

\footnotetext{
"Bem, sabemos que não podemos levantar o tapete, por isso temos de o esticar o mais em baixo possível sem levantar" (T1)

"Quando já esticámos o tapete e podemos trabalhar no estaleiro, aí sabemos que estamos em segurança e que não haverá acidentes” (T2)

"Quer dizer que mesmo com os fios, se conseguirmos passar por baixo, não há problema; esticámos o tapete, não há problema, podemos andar para a esquerda e para a direita [apenas o tapete se movimenta não a máquina em si] (T3)

"Se for muito baixo, não posso esticar o meu tapete e acabou-se" (T4)
}

Estes dados são coerentes com o que observámos durante uma entrega de betão, na presença de uma linha telefónica, numa vivenda situada num aldeamento em zona rural (Vidal-Gomel et al. 2005 a). O operador gere riscos de deterioração da linha (nalgumas empresas, também se trata de riscos de sanção). A entrega é efectuada com tapete, passando através de uma lucarna do telhado. Na situação observada, uma linha telefónica existente ao longo da estrada poderia representar um obstáculo para instalar o tapete. A linha é tida em consideração : o tapete não é muito levantado e o operador efectua uma rotação para o "afastar" da linha. Ele coloca então a máquina em situação de descarga. Acabada a descarga, é necessário deslocá-la para proceder à lavagem. A máquina é deslocada com o tapete baixado. $O$ tapete é posicionado a cerca de 1,20 metros do solo e a 160 graus da cabine do camião. Fica assim "à vista" (do lado esquerdo), quando se põe a cabeça de fora da cabine de condução. A máquina é seguidamente instalada na estrada, numa parte desobstruída do terreno para poder receber as águas de limpeza. $O$ posicionamento do tapete também facilita a arrumação : o tapete encontra-se do lado certo para ser arrumado, o operador recolhe cada um dos elementos do braço articulado, as rotações são efectuadas num eixo afastado da linha.

- Assim apesar da linha telefónica não apresentar os mesmos riscos do que uma linha eléctrica, verifica-se que são aplicadas as mesmas regras enunciadas pelos operadores entrevistados : passar debaixo da linha e só depois efectuar movimentos laterais do tapete sem deslocar a máquina, manter o tapete o mais afastado possível da linha nas diversas fases do trabalho. Três operadores que conduzem quer uma auto-bomba quer uma bomba misturadora, exprimem a regra "passar debaixo da linha" em relação com metaconhecimentos : 
"Debaixo do fio para poder estar perto da rede, para poder ver se estou perto de mais ou não" (P2)

“... temos cuidado, 5 metros e isso tudo, mas... quando olhamos para uma lança destas ficamos sem saber se temos 5 metros ou se não são 2" (P3)

“A vista engana e ... por baixo pelo menos consigo avaliar, vejo onde está a minha lança, vejo os fios” (P4) aproximação, conceito pragmático. No entanto “ao passar debaixo da linha”, operador deve ter em conta o risco de a máquina se virar, o que faz intervir o conceitoem-acto de momento. 0 risco de oscilação depende da possibilidade de estabilizar a máquina em função do estado dos solos e/ou do espaço disponível, do estado de arrumação do estaleiro (esquema 2). Estas diversas dimensões seriam cruciais para as actividades de diagnóstico dos operadores e determinariam a decisão para efectuar ou não a entrega. 
Esquema 2 : As diversas variáveis e conceitos em jogo na gestão dos riscos de capotamento e de contacto com uma linha eléctrica aérea

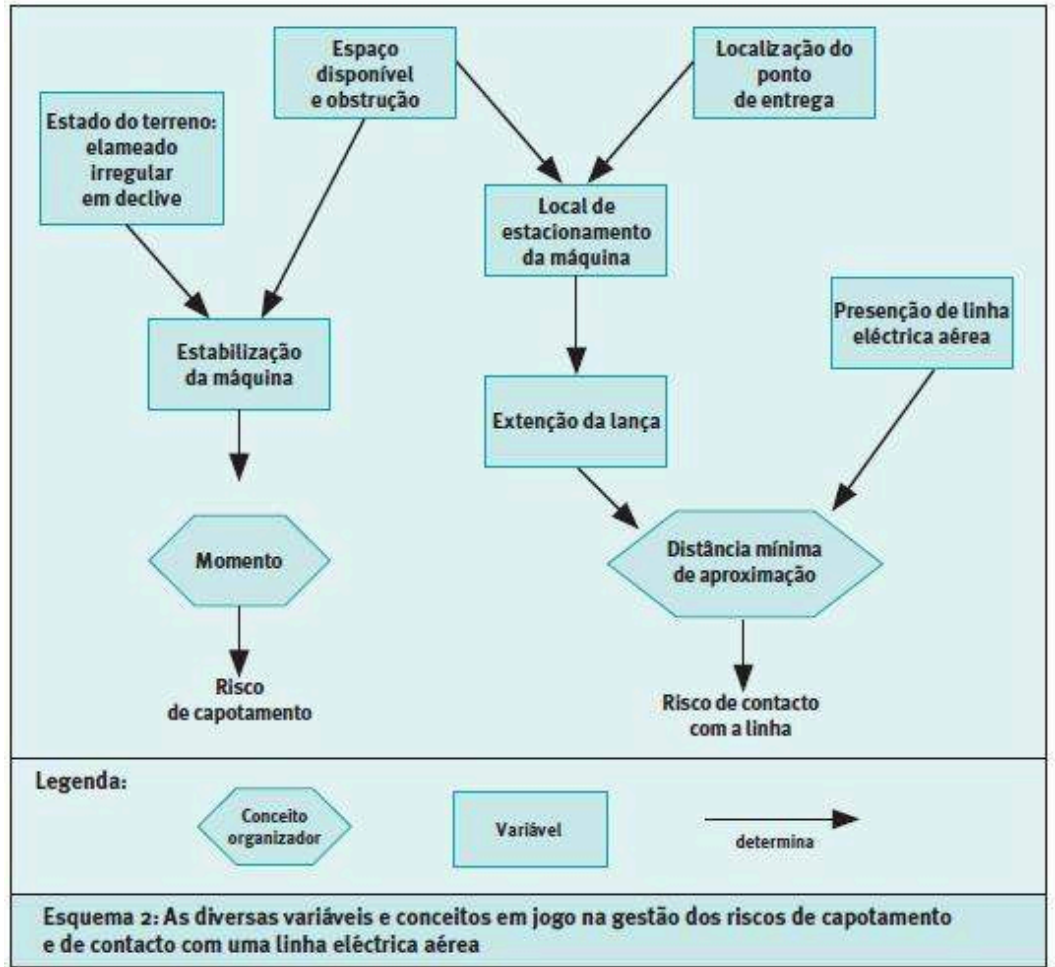

Estas análises das variáveis e conceitos permitem-nos caracterizar saberes de referência que intervêm na identificação do perigo e dos riscos e na gestão do risco em situação. No entanto, são insuficientes para dar conta do conjunto das actividades de gestão dos riscos dos operadores. De facto, em matéria de entrega de betão gerir os riscos profissionais não significa apenas ser capaz de os identificar em situação e de os gerir quando a situação o permite ou de recusar a entrega; torna-se fulcral fazer aceitar a decisão de não proceder à entrega atendendo aos riscos identificados.

Para o evidenciar, tentámos perceber quais as margens de manobra de que dispõem os operadores e as arbitragens que são levados a fazer entre os diferentes pólos do seu sistema de trabalho.

\section{Estará o operador em condições de fazer aceitar que não procede à entrega ?}

Nos diversos contactos que tivemos com o pessoal de chefia ou com os operadores, e nas entrevistas efectuadas, identificámos pressões a que podem ser sujeitos os operadores. Podem ser originadas quer pela sua chefia directa, quer pelo quadro da empresa que fabrica o betão (quem adjudica a encomenda), quer ainda pelo encarregado do estaleiro (o cliente) (Vidal-Gomel et al., 2007).

Por exemplo, um quadro que dirige uma central de betão explica-nos a importância que representa para ele "satisfazer o cliente" e a necessidade de manter as pequenas empresas de construção como cliente. Os "grandes estaleiros" feitos pelas empresas mais importantes do sector não são tão frequentes. Mais numerosas, as pequenas empresas permitem atingir um volume de negócios relativamente estável. Neste sector 
profissional a concorrência é considerável e, no grande grupo a que pertence, este quadro é avaliado com base no volume de negócios atingido. Por isso, não é surpreendente que ele faça pressão sobre os operadores de entrega de betão nalgumas situações. Tivemos, aliás, oportunidade de observar uma situação muito tensa por causa de um entregador se ter recusado a efectuar uma entrega no final do dia, depois de um dia carregado e um número de horas de trabalho avultado (cerca de $10 \mathrm{~h}$ ). Por outro lado, como já referimos, a planificação do operador de entrega de betão é elaborada pela central de betão, que determina o seu tempo de trabalho, o número de estaleiros a fornecer, etc. Noutra empresa do mesmo grande grupo, os operadores de entrega de betão explicam que, mesmo que o responsável da central de betão não faça directamente pressão para proceder à entrega quando eles pensam que os riscos são demasiado elevados, é mal visto voltar para a central sem ter efectuado a entrega.

Pressões importantes podem também ser exercidas pelo encarregado de estaleiro, como o comprova o seguinte exemplo que nos foi relatado por um quadro de uma empresa de entrega $\left[{ }^{10}\right]$ :

Um condutor de auto-bomba, pouco experiente, tem uma entrega para efectuar num "grande" estaleiro; a empresa cliente pertence a um grupo importante do sector da Construção Civil e Obras Públicas. Ele tinha recusado uma entrega na véspera, atendendo aos riscos que corria. Chegando ao estaleiro e verificando a proximidade das linhas eléctricas aéreas com o ponto de descarga, recusa-se novamente a efectuar a entrega. $O$ encarregado de estaleiro insiste então e ameaça aplicar penalidades financeiras à central de betão se o condutor não proceder à entrega. Sob esta pressão, ele aceita. Enquanto descarregava, o braço articulado da auto-bomba colidiu com a linha eléctrica. Estando a trabalhar com comando à distância, o condutor não estava em contacto com a máquina e não se encontrava mais nenhum operador na zona perigosa. $\mathrm{O}$ incidente eléctrico pode ser recuperado : o condutor saiu da zona e pediu para que esta fosse sinalizada.

Este exemplo é revelador das decisões que os operadores são levados a tomar entre objectivos contraditórios : os objectivos relacionados com a segurança - neste exemplo o operador tinha identificado o risco de acidente -, e os relacionados com a pressão exercida pelo cliente - aqui trata-se de ameaças de sanções; noutros casos, o encarregado de estaleiro chama directamente a concorrência -, os relativos à sua relação entre a central de betão e a empresa de entrega para a qual ele trabalha, tudo em função das margens de manobra de que dispõe ou julga dispor: na véspera tinha recusado uma entrega, em situação não contactou com o seu superior hierárquico, conforme previsto nos procedimentos. Todos esses elementos contribuíram para despoletar uma situação de saturação (Benchekroun et al., 2002 ; Bourgeois et al., 2003).

De forma geral, podemos destacar a importância do cliente nas decisões que são tomadas, da mesma forma que se verifica no sector das relações de serviços. De facto, as empresas contemporâneas inscrevem-se numa "economia da singularidade" (d'Iribarne, 2005) ou num "produtivismo reactivo" (Askenazy, 2004) que consiste, nomeadamente, em oferecer serviços à medida dos seus clientes. Deste modo, o sector produtivo, mesmo quando se trata de produzir bens industriais, utiliza a noção de serviço como argumento central. A entrega de betão, ainda que realizada no âmbito do sector da Construção, pode ser analisada como uma actividade de serviço, iniciada pelo encarregado de estaleiro aquando da encomenda e terminada no mesmo, após a entrega do betão, quando assina a guia de remessa (Vidal-Gomel et al., 2007). 
Finalmente, requer alguma cooperação entre a fábrica de betão, a empresa de distribuição mas também o estaleiro. Tudo passa pelo operador de entrega de betão que se encontra no centro de relações complexas entre estes três tipos de empresas : o fornecedor do estaleiro-cliente é para o operador de entrega de betão quem dá a ordem ; o operador de entrega de betão, por sua vez, é o "representante" do fornecedor para o estaleiro-cliente mas também é um actor da actividade colectiva quando procede à entrega de betão no estaleiro. Neste caso, segundo os diferentes pólos de uma situação de trabalho identificados por Caroly et Weill-Fassina (2007), o pólo sistema compõe-se de duas entidades : o empregador e o "dador de ordem", que devem colaborar para fazer o serviço, mas que têm objectivos divergentes. A complexidade das relações que podem existir entre estas duas entidades é uma fonte de dificuldades para o operador, nomeadamente para conseguir elaborar estratégias de regulação eficientes.

Neste contexto, o operador de entrega de betão parece dispor de uma estreita margem de manobra para poder regular o sistema e de um fraco poder de decisão, pelo menos nalguns aspectos.

Com efeito, a recusa de uma entrega por causa dos riscos não é interpretada pelos operadores de entrega de betão, nem pelos restantes profissionais desta área como um direito de recusar o trabalho numa situação perigosa. Pouco informados, nem os representantes do pessoal da empresa de entrega, nem os do estaleiro podem desencadear um procedimento de alerta. Quando este direito é reconhecido, é o de forma restritiva : por um lado, costuma ser atribuído apenas aos operadores da entrega, apesar do risco envolver todos os actores presentes nesse momento ; por outro lado, considera-se frequentemente que necessita do acordo das chefias. Nas entrevistas efectuadas (quadro 2), um condutor de tapetes em cada quatro deparou-se com uma situação de risco devido ao facto do acesso ao estaleiro ser demasiado estreito. Contactou a central de betão para solicitar autorização para se retirar. Este procedimento foi-nos assinalado por três condutores de auto-bombas ou de bombas misturadoras em cada quatro.

Este procedimento é problemático sobre vários pontos de vista :

- É problemático do ponto de vista do direito de trabalho.

- É também problemático porque faz do reconhecimento das competências do operador e da confiança entre o quadro responsável e o operador um dos pontos-chave da prevenção dos riscos profissionais. No exemplo do incidente referido, o operador pouco experiente, que já tinha recusado uma entrega na véspera, não contacta a chefia, contrariamente ao previsto pelo procedimento, e aceita a entrega apesar do risco identificado.

- Este procedimento levanta questões sobre as dimensões cognitivas da actividade : estará a chefia responsável em posição de avaliar a situação a partir do descritivo fornecido pelo operador? Alguns responsáveis disseram-nos que podiam deslocar-se para examinar a situação. Sendo eles antigos operadores de entrega de betão, os seus diagnósticos são com certeza fiáveis, mas uma decisão dessas também se baseia naquilo que o operador conhece das suas próprias competências : as situações que ele domina, ou não, mais ou menos bem, etc. Ou seja, este tipo de actividade de diagnóstico não necessita apenas de competências relativas às características da situação a tratar mas também os meta-conhecimentos do operador, conforme exposto por Valot (Valot et al., 1993 ; Valot, 2001). O que significa então tomar uma decisão que será executada por outrem? 


\section{Conclusão}

Neste artigo, pretendemos evidenciar a necessidade de dar maior relevo aos contributos conjuntos da didáctica profissional e da ergonomia, com o objectivo de prevenção dos riscos profissionais. O nosso projecto vai de encontro ao de Lacomblez (2001) e de Teiger e Lacomblez $(2005,2006)$ no sentido de articular análise de trabalho para transformar as situações de trabalho e para o desenvolvimento dos operadores, com vista a contribuir para a prevenção dos riscos profissionais. Diferenciamo-nos, no entanto, ao procurar caracterizar os saberes profissionais de referência com base nos quais serão elaborados os conteúdos da formação. Deste ponto de vista, construímos uma abordagem complementar entre análise ergonómica do trabalho e didáctica profissional da qual podemos sintetizar alguns aspectos e a partir dos quais podemos especificar orientações para a formação e para a transformação das situações de trabalho.

Por um lado, colocando a tónica sobre as dimensões cognitivas da actividade e em particular as conceptualizações em jogo, a didáctica profissional leva-nos a caracterizar aspectos dos saberes profissionais de referência que podem constituir o alvo da formação, e a especificar situações de formação que poderiam permitir a sua aquisição pelos operadores. Neste estudo, trata-se simultaneamente dos elementos da teoria do risco identificados e da articulação entre a distância mínima de aproximação e a noção de momento.

De facto, as formações propostas aos operadores de entrega de betão dividem a relação actividade-situação em função dos tipos de riscos : o risco de capotamento da máquina é apresentada independentemente do risco eléctrico. Acontece que em algumas situações, o operador deve ter em consideração estes dois tipos de riscos, o que obriga a elaborar um diagnóstico da situação integrando ao mesmo tempo a noção de momento e as suas relações com diversos tipos de variáveis (a posição da máquina e a extensão da lança da máquina, etc.), e a noção de distância mínima de aproximação e as suas relações com diversas variáveis da situação. Assim, parece importante não subdividir sistematicamente o real em função de riscos-tipo, mas ter em consideração a estreita relação entre as características das situações, a actividade e as competências integrando as conceptualizações. Tal subdivisão produz efectivamente uma separação das variáveis em jogo (no sentido de Samurçay \& Rogalski, 1998) na actividade de gestão dos riscos dos operadores.

81 Julgamos que, se pretendermos guiar a articulação entre diferentes dimensões das competências, é uma aprendizagem baseada neste conjunto que deve ser privilegiada durante a formação. Finalmente, a modesta duração da formação inicial remete importantes desafios de prevenção para a "formação no terreno" e a "formação contínua".

Uma proposta de formação contínua poderia inserir-se no âmbito das jornadas "Pôr em funcionamento com segurança as bombas de betão" sugerida pelo ramo profissional [11]. A partir de filmes ou de fotografias de estaleiros, o formador poderia, por exemplo, orientar a troca de conhecimentos lançando o debate sobre :

- regras tais como "passar debaixo dos fios" ou "afastar a máquina da linha";

- meta-conhecimentos tais como "a vista engana";

- ter em conta a distância mínima de aproximação e do momento, não com base numa definição do próprio conceito, mas a partir dos indicadores que os operadores 
estabeleceram ; desta forma, o risco de capotamento de uma máquina compreende-se com base no conceito de momento em função da posição da lança, o estado do solo, da possibilidade de estabilizar a máquina ou não.

Os debates no seio do grupo de participantes poderiam ser alimentados modificando algumas varáveis da situação (estado do solo, espaços de trabalho, possibilidade ou não de esticar todos os estabilizadores da máquina, etc.). Este tipo de formação poderia ser útil para completar as formações ministradas nas empresas.

Ao focalizar-se sobre as competências relativas ao objecto do trabalho, a didáctica profissional, tal como defendida, por exemplo, por Pastré, Mayen e Vergnaud (2006), deixa em suspenso o conjunto do sistema socio-organizacional no qual se insere o operador. De facto, o nosso estudo sublinha que não basta apenas formar os operadores para que eles estejam em condições de identificar e de gerir uma situação com riscos, é preciso também que eles tenham a possibilidade de recusar fazer a entrega quando os riscos identificados são demasiado grandes. Ou seja, para poderem chegar a um compromisso eficaz e pertinente necessitam dispor de margens de manobra. Aumentar essas margens implica, não só actuar sobre as relações entre a hierarquia da empresa de entrega e da fábrica de betão mas também sobre a evolução das relações com o estaleiro.

Verificámos que os operadores dispõem de um fraco poder de decisão quando se trata do direito de recusar o trabalho nas situações perigosas - o que pode depender tanto da central de betão como da chefia directa. Paradoxalmente, noutras situações, quando avançam em "marcha forçada" para, apesar do detector de linhas eléctricas aéreas ter imobilizado a máquina, poderem ainda assim efectuar a entrega, são considerados "responsáveis" caso haja algum problema :

Poderiam ser implementadas várias pistas de transformação dirigidas às chefias intermédias e aos estaleiros.

87 Trata-se de intervir simultaneamente junto da estrutura de enquadramento da entrega e da fabricação de betão. Tal como Benchekroun, Bourgeois e Hubault (2002), verificámos que a chefia mais próxima desempenha um papel importante na prevenção e que é necessário dar-lhe meios para arbitrar de maneira a privilegiar mais a prevenção dos riscos profissionais. Um grande grupo que participou neste estudo, remunera de forma diferenciada um chefe de fabricação e um chefe de entrega : para o primeiro, o enfoque é colocado no volume de negócios, já para o segundo, a prevenção dos riscos profissionais constitui um critério da remuneração. Porém, o primeiro é também um actor determinante na prevenção dos operadores de entrega de betão. Por isso, uma das nossas propostas de reflexão estava relacionada com a inclusão da prevenção dos riscos profissionais nos critérios de avaliação destes dois tipos de quadros (Vidal-Gomel et al., 2007).

88 Para complementar, trata-se de permitir a esses actores que compreendam a complexidade do trabalho dos operadores e que lhes seja reconhecida a possibilidade de tomar decisões em situação, nomeadamente no que diz respeito ao direito de recusar o trabalho em situações perigosas. Revela-se também necessário poder ter uma mais ampla actuação sobre os quadros destes sectores profissionais, compostos também por empresas de entrega de tamanho mais modesto, a que se recorre, na maioria das vezes, como subcontratados "externos" (outsourcing). Assim, para uma grande empresa da região de Paris, contamos 15 operadores de entrega de betão que pertencem ao grupo 
(subcontratação interna) e 400 à principal empresa subcontratada. Nestes casos, as condições de trabalho poderiam ser mais prejudiciais, à semelhança das condições de trabalho dos operadores das empresas subcontratadas do sector da Construção (Jounin, 2008).

No que diz respeito aos estaleiros, o desafio coloca-se em conseguir que os riscos associados às actividades de entrega sejam devidamente valorizados. Foram aqui evidenciadas as pressões que podiam ser exercidas pelo encarregado de estaleiro sobre os operadores, mas não são as únicas dificuldades para os operadores de entrega de betão : espaços insuficientes, congestionamento, etc. também podem estar na origem dos acidentes que afectam a distribuição (Vidal-Gomel et al., 2007). Os estaleiros não estão "preparados" para antecipar os constrangimentos reais da entrega. A acção dirigida para este tipo de intervenientes poderia abordar os temas da tomada de consciência dos riscos associados à entrega de betão, tanto do ponto de vista do operador de entrega de betão como para o conjunto das pessoas presentes no estaleiro na altura da entrega, e os desafios do direito de se retirar do trabalho em situações perigosas para os operadores de entrega de betão.

Foi assim que, numa primeira iniciativa de um ramo profissional deste sector, foi concebido e divulgado um DVD, nomeadamente para informar o sector da Construção. Nele são apresentados os riscos eléctricos da entrega e evocados os procedimentos e a regulamentação a aplicar. Mais modificações estão a decorrer nomeadamente para facilitar o exercício do direito de recusar o trabalho por parte dos operadores de entrega de betão em situações perigosas. Estas modestas transformações demonstram uma certa evolução por parte de alguns dos actores do sector profissional da entrega de betão.

91 Em conclusão, este estudo salienta que, os pedidos de formação dos operadores de primeira linha podem, não só, dissimular disfunções do sistema de trabalho e problemas nas condições de trabalho, como também, a necessidade de intervir junto de outros actores do sistema. Uma vez esclarecidos esses pontos, a didáctica profissional fornece-nos ferramentas eficazes. Com o objectivo de instruir directamente, permitenos, orientar a análise para saberes profissionais de referência e proporcionar formação na área dos riscos profissionais, não apenas através da abordagem dos aspectos técnicos e regulamentares, mas também, focalizando as relações entre "situação e actividade" e dando relevo às características das situações que necessitam ser transportadas para a formação para facilitar a sua aprendizagem. o desfasamento produzido deveria permitir evitar uma subdivisão em função dos tipos de riscos sabendo-se que é fulcral que, em situação, sejam tomados em conta conjuntamente.

\section{BIBLIOGRAFIA}

Amalberti, R. \& Hoc, J.-M. (1999). Analyse des activités cognitives en situation dynamique : d'un cadre théorique à une méthode. Le travail humain, 62 (2), 97-129. 
Aszkenazy, P. (2004). Les désordres du travail. Enquête sur le nouveau productivisme. Paris : Seuil \& La république des idées.

Benchekroun, H., Bourgeois, F., \& Hubault, F. (2002). Comment aider l'encadrement de proximité à faire des arbitrages face à des situations à risque. In J.-M. Evesque, A.-M. Gautier, C. Revest, Y. Schwartz \& J.-L. Vayssiere (Eds.), Actes du XXXVII ${ }^{e}$ congrès de la Société d'ergonomie de langue française : "Les évolutions de la prescription" (pp. 377-395). Aix-en Provence : GREACT, SELF (en ligne : http://www.ergonomie-self.org/actes/congres2002.html).

Boreham, N., Samurçay, R. \& Fischer, M. (Eds.) (2002). Work process knowledge. London: Taylor \& Francis.

Bourgeois, F., \& Van Belleghem, L. (2003). Avec l'approche travail dans l'évaluation des risques professionnels (décret 5/11/01), enfin du nouveau en prévention. Séminaire Paris 1: "Travailler, une expérience quotidienne du risque ?" 19-23 mai 2003.

Cannon-Bowers, J. E., Salas, E., \& Converse, S. (1993). Shared Mental Models in Expert Team Decision-Making. In J. Castellan, (Ed.), Individual and Group Decision-Making: Current Issues (pp. 221-246). Hillsdale, $\mathrm{NJ}$ : Lawrence Erlbaum Associates.

Caroly, S., \& Weill-Fascine, A. (2007). En quoi les différentes approches de l'activité collective des relations de services interrogent la pluralité des modèles de l'activité en ergonomie ? @ctivités, 4 (1), 85-98, http://www.activites.org/V4n1/v4n1.pdf.

Cawley, J.C., \& Homce, G.T. (2003). Occupational injuries in the United Sates, 1992-1998, and recommendations for safety research. Journal of Safety Research, 34, 241-248.

Chi, C.-F., Yang, C.-C., \& Chen, Z.-L. (2009). In-depth accident analysis of electrical fatalities in the construction industry. International Journal of Industrial Ergonomics, 39 (4), 635-644.

Clot, Y. Daniellou, F., Jobert, G., Mayen, P., Olry, P., \& Schwartz, Y. (2005). Travail et formation : les bénéfices d'une analyse exigeante (table ronde). Éducation permanente, 165, 139-160.

Coutarel, F., Daniellou, F., \& Dugué, B. (2003). Interroger l'organisation du travail au regard des marges de manœuvre en conception et en fonctionnement. La rotation est-elle une solution aux TMS ? Pistes, 5 (2), http://www.pistes.uqam.ca/v5n2/articles/v5n2a2.htm.

Cru, D. (1995). Règles de métier, langue de métier : dimension symbolique du travail et démarche participative de prévention. Le cas du bâtiment et des travaux publics. Diplôme de l'EPHE. Paris: laboratoire d'ergonomie.

Daniellou, F. (2005). The French-speaking ergonomists' approach to work activity: crossinfluences of field intervention and conceptual models. Theoretical issues in ergonomics science, 6 (5), 409-427

Dei-Svaldi, D., Paques, J.-J., \& Gillet, J.-C. (1992). Contacts directs d'engins avec les lignes électriques aériennes. Cahiers des notes documentaires, 147, 177-194.

Gaudart, C. \& Weill-Fassina, A. (1999). L'évolution des compétences au cours de la vie professionnelle. Formation Emploi, 67, 47-62.

Gonzàlez, R. \& Weill-Fassina, A. (2005). Modalités de régulation du processus de travail dans les activités de service en crèche. @ctivités, 2 (2), 2-23, http://www.activites.org/V2n2/gonzales.pdf.

Hale, R. H., \& Glendon, I. A. (1987). Individual behaviour in the controle of danger. Amsterdam : Elsevier.

Iribarne, A. (de) (2005). Vers un modèle de production néo-artisanal de services sur mesure numérisés? Formation professionnelle, 36, 5-15. 
Janicak, A. C. (2008). Occupational fatalities due to électrocutions in the construction industry. Journal of Safety Research, 39, 617-621.

Jounin, N. (2008). Chantier interdit au public. Enquête parmi les travailleurs du bâtiment. Paris : La découverte.

Lacomblez, M. (2001). Analyse du travail et élaboration des programmes de formation professionnelle. Relations industrielles/Industrial relations, 56 (3), 387-536.

Leplat, J. (1997). Regards sur l'activité en situation de travail : Contribution à la psychologie ergonomique. Paris : PUF.

Leplat, J. (2002). Psychologie de la formation. Jalons et perspectives. Choix de textes (1955-2002). Toulouse : Octarès.

Leplat, J. (2008 a). Formation et didactique professionnelle : un chemin psychologique dans l'histoire. Travail et Apprentissages, 1, 22-33.

Leplat, J. (2008 b). Repères pour l'analyse de l'activité en ergonomie. Paris PUF.

Leplat, J. \& Cuny, X. (1977). Introduction à la psychologie du travail. Paris : PUF.

Mayen, P., \& Savoyant, A. (1999). Application de procédures et compétences. Formation Emploi, 67, 77-92.

Montmollin, M. (de) (1974). L'analyse du travail préalable à la formation. Paris : Armand Colin.

Paques, J.-J. (1995). Expérimentation d'un dispositif limiteur de portée pour grue mobile et évaluation des distances aux lignes électriques. Études et Recherches, Rapport R-096. Québec : IRSST.

Pastré, P. (2005). La conception des situations didactiques à la lumière de la théorie de la conceptualisation dans l'action. In P. Rabardel \& P. Pastré (Eds.), Modèles du sujet pour la conception (pp. 73-107). Toulouse : Octarès.

Pastré, P., Mayen, P., \& Vergnaud, G. (2006). La didactique professionnelle. Revue française de pédagogie, 154, 1-55.

Puéyo, V. (1999). La traque des dérives : expérience et maîtrise du temps, les atouts des anciens dans une tâche d'autocontrôle. Travail et Emploi, 84, 63-73.

Rogalski, J., \& Samurçay, R. (1994). Modélisation d'un savoir de référence et transposition didactique dans la formation de professionnels de haut niveau. In G. Arsac, Y. Chevalard, J.-L. Martinand, \& A. Tiberghien (Eds.), La transposition didactique à l'épreuve (pp. 35-71). Grenoble : La pensée sauvage.

Rogalski, J., Marquié, J.-C. (2004). Évolution des compétences et des performances. In J.-M. Hoc \& F. Darses (Eds.), Psychologie ergonomique : tendances actuelles (pp. 141-173). Paris : PUF.

Samurçay R., \& Pastré P. (Eds) (2004). Recherches en didactique professionnelle. Toulouse : Octarès.

Samurçay, R., \& Pastré, P. (1995). La conceptualisation des situations de travail dans la formation des compétences. Éducation permanente, 123, 13-31.

Samurçay, R., \& Rogalski, J. (1998). Exploitation didactique des situations de simulation. Le Travail humain, 61(4), 333-359.

Teiger, C. \& Lacomblez, M. (2005). L'ergonomie et la trans-formation du travail et/ou des personnes (1 ${ }^{\text {ère }}$ partie). Éducation permanente, 165, 9-28.

Teiger, C. \& Lacomblez, M. (2006). L'ergonomie et la trans-formation du travail et/ou des personnes (2 ${ }^{\mathrm{e}}$ partie). Éducation permanente, 166, 105-114. 
Terssac, G. (de), \& Chabaud, C. (1990). Référentiel opératif commun. In J. Leplat \& G. de Terssac (Eds) : Les facteurs humains de la fiabilité dans les systèmes complexes (pp. 111-139). Toulouse : Octarès.

UTE C 18-510 (1991). Recueil d'instructions générales de sécurité d'ordre électrique. Paris : Union technique de l'électricité (première édition : 1988).

Valot, C. (2001). Rôle de la métacognition dans la gestion de situations dynamiques. Psychologie française, 46 (2), 131-141.

Valot, C., Grau, J.-C., \& Amalberti, A. (1993) Les métaconnaissances : des représentations de ses propres connaissances. In A. Weill-Fassina, P. Rabardel, \& D. Dubois (Eds). Représentations pour l'action (pp. 271-293). Toulouse : Octarès.

Vergnaud, G. (1990). La théorie des champs conceptuels. Recherche en didactique des mathématiques, $10(2-3), 133-170$.

Vidal-Gomel, C. \& Rogalski, J. (2007). La conceptualisation et la place des concepts pragmatiques dans l'activité professionnelle et le développement des compétences. @ctivités, 4 (1), 49-84, http://www.activites.org/v4n1/v4n1.pdf.

Vidal-Gomel, C., Olry, P., Jeanmougin, H. \&, Lanoë, D. (2005 a). Gestion des risques électriques par des non professionnels de l'électricité. Rapport final : l'activité de livraison de béton. Convention Ministère du travail, de la solidarité et des affaires sociales - CNRS - Université Paris 8. Saint-Denis : Université Paris 8.

Vidal-Gomel, C., Olry, P., Jeanmougin, H. \&, Lanoë, D. (2005 b). Une approche préalable de l'analyse de l'activité et des compétences. Les risques professionnels dans la livraison de béton. Éducation permanente, 165, 47-65.

Vidal-Gomel, C., Olry, P., Lanoë, D., \& Jeanmougin, H. (2007). La livraison de béton : système de travail et prévention des risques professionnels. In M. Zouinar, G. Valléry, \& M.-C. Le Port (Eds.), Actes du $42^{\text {ème }}$ Congrès de la SELF : "Ergonomie des produits et des services" (pp. 655-665). Saint-Malo : 4-6 septembre. Toulouse : Octarès.

Weill-Fassina, A. (2008). Ergonomie et Formation : Chassés-Croisés. Travail et Apprentissages, 1, 34-50.

Weill-Fassina, A. \& Pastré, P. (2004). Les compétences professionnelles et leur développement. In P. Falzon (Ed.), Ergonomie (pp. 213-231). Paris : PUF.

\section{NOTAS}

1. Os trabalhos de Lacomblez (2001), Leplat (2002, 2008 a), Teiger e Lacomblez $(2005,2006)$, ou ainda de Weill-Fassina (2008) evocam e analisam as relações entre análise ergonómica do trabalho e formação. Apenas alguns elementos serão aqui retomados para especificar a nossa abordagem.

2. Embora exista um grupo da Associação Internacional de Ergonomia dedicado às questões da formação já há mais de uma década, se considerarmos o elevado número de intervenções e de pesquisas desenvolvidas sobre outros temas, a questão da formação mantém-se em segundo plano.

3. O pedido efectuado pela Direcção das Relações do Trabalho (DRT, CT3) incidia sobre os riscos eléctricos para não profissionais de electricidade. Análises previamente efectuadas aos relatórios de acidentes, levaram-nos a reformular esse pedido para atentarmos aos riscos eléctricos 
envolvidos no decorrer de uma entrega de betão pronto (Vidal-Gomel et al., 2005 b). Este objectivo coincidiu com as preocupações de dois sindicatos profissionais do sector "pedreiras e materiais", e, duas empresas que pertenciam ao mesmo grupo internacional que decidiram, numa fase inicial, contribuir para esta pesquisa. Esse grupo engloba um ramo "granulados e betão", que fabrica o betão pronto. Em França, este ramo está presente em 60 Departamentos [NT2] e está organizada de forma descentralizada, por regiões. Com vista a evitar a dependência exclusiva de empresas externas para o transporte de betão mantiveram-se algumas dessas empresas neste ramo (ao contrário da tendência geral para o outsourcing). Têm como principal cliente as fábricas de betão regionais. Por isso, os dados recolhidos são referentes a empresas subcontratadas internamente no seio de um grande grupo. A primeira empresa de transporte que participou na nossa investigação está estabelecida na região Centro, e a segunda na região Ile-deFrance. A terceira empresa de transporte que participou mais recentemente neste estudo é da região Ile-de-France. Pertence a outro grande grupo internacional concorrente. Tivemos assim a oportunidade de aceder a uma variedade de estaleiros em zona urbana, semi-urbana ou rural.

[NT 2] -Nota de tradução 2: Departamento - trata-se de uma divisão administrativa do território francês. Existem 100 Departamentos, dos quais 2 situados na Ilha da Córsega e 4 nas regiões ultramarinas.

4. Tanto mais que os acidentes que nos interessam estão incluídos no conjunto dos acidentes de origem eléctrica, o que torna impossível a sua identificação.

5. Neste caso, em França, deveria ter sido solicitada uma "declaração de intenção de início de obras" (DICT, Decreto $n^{\circ}$ 91-1147 de 14.10.1991) o que poderia ter levado à desactivação temporária da linha. Para além disso, a norma UTE C18-511 (1991) obriga a que seja definida a "distância mínima de abordagem" (distância a manter entre a máquina e a linha eléctrica para evitar produzir um arco eléctrico) e, a partir daí : que seja definida uma zona de afastamento, delimitado um itinerário e os lugares adequados para as máquinas, e estabelecida vigilância por pessoal competente. Tal não exclui que o operador seja levado a gerir a distância entre o braço da máquina e a linha eléctrica aérea.

6. Nota de tradução 1: Refere-se aqui ao termo francês "compagnon", com origem na organização corporativa dos ofícios/profissões caracterizada por uma estrutura interna em três graus: o companheiro representa o segundo grau, situando-se entre o aprendiz ( $1^{\circ}$ grau) e o mestre ( $3^{\circ}$ grau). No caso de um estaleiro, quando se fala de "companheiro" entende-se "operário qualificado/experiente".

7. Artigo L. 231-8 do Código do trabalho francês que define o direito de um assalariado de recusar o trabalho numa situação de trabalho quando tiver um motivo razoável para pensar que esta representa um perigo grave e iminente para a sua vida ou saúde, sem que qualquer sanção lhe possa ser aplicada (nomeadamente o despedimento).

8. Definimos a teoria, como um conjunto de conhecimentos, dando a explicação completa de um certo número de factos.

9. Em caso de incidente, como para qualquer rede eléctrica, um sistema de protecção dispara e desliga a rede. As linhas eléctricas aéreas, são colocadas automaticamente sob tensão, várias vezes, antes do corte definitivo. Assim evita-se desligar uma parte importante da rede cada vez que se produz um incidente menor.

10. Este incidente ocorreu no final da nossa intervenção na empresa, o que não permitiu que os dados fossem recolhidos por nós próprios. Tanto quanto sabemos, também não foi analisado detalhadamente na empresa.

11. Inúmeras propostas poderiam ser efectuadas para transformar as formações existentes, nomeadamente no que toca a não apresentar as causas de acidentes como resultado exclusivo de erros cometidos pelos operadores de primeira linha ou no sentido de proporcionar uma discussão alargada sobre a adaptação das regras às características das situações. 


\section{RESUMOS}

Este artigo apresenta um estudo sobre a gestão dos riscos no sector de entrega de betão pronto nos estaleiros de construção civil ou de obras públicas. A nossa análise articula contributos da ergonomia para entender o funcionamento do sistema de trabalho, identificar factores de risco e propor pistas de transformação desse sistema num objectivo de prevenção, e contributos resultantes da didáctica profissional procurando identificar um referencial de saberes profissionais por forma a transpor as características de situações de trabalho favorecendo a sua aquisição directa pelos operadores, através de formação inicial ou contínua. Este duplo enfoque permite mostrar que, neste sector profissional, para estes operadores, gerir os riscos profissionais não significa ser capaz de identificá-los no terreno e de os gerir quando a situação o permite ou mesmo de recusar a entrega : é fundamental ser capaz de fazer aceitar a decisão de não entrega, com base nos riscos identificados.

Este artículo presenta un estudio sobre la gestión del riesgo en el área de entrega de hormigón listo para utilización en trabajos de construcción o en obras públicas. Nuestro análisis articula dos tipos de contribuciones : la ergonomía y la didáctica profesional. Con la ergonomía se busca comprender el funcionamiento del sistema de trabajo, identificar factores de riesgo y sugerir formas de transformación del sistema en una perspectiva de prevención. Desde el punto de vista de la didáctica profesional se busca identificar el referencial de conocimientos profesionales e interesarse a la transposición de características de situaciones de trabajo que puedan facilitar la adquisición de los operadores con el objetivo de instrucción directa en formación inicial o continua. Este doble enfoque nos permite demostrar que en el sector profesional analizado, para los operadores responsables de la prestación, gestionar los riesgos profesionales no significa únicamente ser capaz de identificarlos y manejar situaciones cuando las condiciones lo permiten o negar la entrega, poder imponer la decisión de rechazo de entrega tomando en cuenta los riesgos identificados es crucial.

Cet article présente une étude sur la gestion des risques dans le secteur de la livraison du béton prêt à l'emploi sur les chantiers du bâtiment ou des travaux publics. Notre analyse articule des apports de l'ergonomie pour comprendre le fonctionnement du système de travail, identifier des facteurs de risque et proposer des pistes de transformation de ce système dans un objectif de prévention, et des apports issus de la didactique professionnelle qui conduisent à identifier des savoirs professionnels de référence et à s'intéresser à la transposition des caractéristiques de situations de travail qui pourrait favoriser leur acquisition par les opérateurs, dans un objectif d'instruction directe en formation initiale ou continue. Cette double approche nous permet de montrer que, dans ce secteur professionnel, pour les opérateurs chargés de la livraison, gérer les risques professionnels ne signifie pas être en mesure de les identifier en situation et de les gérer quand la situation le permet ou de refuser de livrer ; être en mesure de faire accepter la décision de ne pas livrer étant donné les risques identifiés est crucial.

This article presents a study on occupational risks management in the area of supply and delivery of ready-to-use concrete on construction sites or public works.. Our analysis articulates the contribution of ergonomics to understand the work system, identify the risks factors and propose change in particular areas of the work system with the aim of preventing occupational risks. Professional didactics contributes to identifying and referencing occupational knowledge by taking an interest in the characteristics of work situations and transferring this knowledge into training situations to facilitate its acquisition by operators, in order to direct instruction in initial or continuing training. This dual approach allows us to show that, in this professional field 
for operators involved in delivery, managing risks does not only mean identifying the risks in a situation and managing them when the situation allows it or refusing to complete the delivery: it is crucial to have the power to decide not to deliver considering the identified risks.

\section{ÍNDICE}

Palabras claves: didáctica profesional, ergonomía, formación, entrega de hormigón, riesgos eléctricos

Mots-clés: didactique professionnelle, ergonomie, formation, livraison de béton, risques électriques

Palavras-chave: didáctica profissional, ergonomia, formação, entrega de betão, riscos eléctricos Keywords: vocational didactics, ergonomics, training, concrete delivery, electric risks

\section{AUTORES}

\section{CHRISTINE VIDAL-GOMEL}

Université Paris 8, UFR de psychologie, 2 rue de la liberté, F-93526 Saint-Denis Cedex 02 christine.vidal@univ-paris8.fr

\section{PAUL OLRY}

AgroSup Dijon, Unité Développement professionnel et formation, 26 Boulevard Petitjean, F-21079

Dijon Cedex

paul.olry@educagri.fr.

\section{YOUCEF RACHEDI}

Université Paris 8, UFR de psychologie, 2 rue de la liberté, F-93526 Saint-Denis Cedex 02 yrachedi@univ-paris8.fr 